\title{
Erratum to: A Randomized Controlled Trial Administration of Tetanus Toxoid (TT) Versus Tetanus and Reduced Diphtheria (Td) in Pregnant Women
}

\author{
Maha M. Salama • Osama A. W. Hady • Wael Ashour • \\ Amal Mostafa $\cdot$ Sahar El Alkamy • Nehad El Sayed • \\ Remon Abu El Yazeed
}

Published online: 25 May 2011

(C) Springer Science+Business Media, LLC 2011

Erratum to: J Clin Immunol (2009) 29:524-531

DOI 10.1007/s10875-009-9289-5

The authors would like to correct the title of the above paper.

The published title is "A Randomized Controlled Trial of Oral Administration of Tetanus Toxoid (TT) Versus Tetanus and Reduced Diphtheria (Td) in Pregnant Women". The correct title is shown above. The words "of Oral" were removed since this vaccine is not given orally but instead should be injected.

The online version of the original article can be found at http://dx.doi. org/10.1007/s10875-009-9289-5.

M. M. Salama • W. Ashour · N. El Sayed

Egyptian Company for Biological Products \& Vaccines,

VACSERA,

Giza, Egypt

O. A. W. Hady $(\varangle) \cdot$ A. Mostafa

National Organization for Drug Control \& Research, NODCAR,

Cairo, Egypt

e-mail: osamahady_2009@yahoo.com

\section{S. El Alkamy}

Egyptian Ministry of Health and Population,

Abu Homos, Beheira Governorate, Egypt

R. A. El Yazeed

U.S. Naval Medical Research Unit Number Three,

Cairo, Egypt 